\title{
Planejamento e controle da produção de cilindros para laminação: um estudo de caso quantitativo
}

\author{
Laerte José Fernandes ${ }^{a}$, Luis Alberto Osés Rodriguez ${ }^{\mathrm{b}}$, \\ Anderson Ribeiro Correia ${ }^{\mathrm{c}}$, Fernando Augusto Silva Marins ${ }^{\mathrm{d} *}$ \\ alaerte.fernandes@villaresrolls.com, Villares Rolls, Brasil \\ bosesrodriguez@yahoo.com.br, Villares Rolls, Brasil \\ correia@ita.br, ITA/CTA, Brasil \\ d*fmarins@feg.unesp.br, UNESP, Brasil
}

\section{Resumo}

Este trabalho apresenta um modelo de otimização-simulação aplicado em um estudo de caso real no setor de cilindros para laminação de uma siderúrgica, buscando melhorar o gerenciamento da área/equipamento gargalo da linha de produção. A simulação atuou em conjunto com um modelo de otimização da programação linear inteira (PLl) para melhorar o atendimento de prazo junto aos clientes em uma produção não seriada. Como resultado deste procedimento combinado da PLl e simulação, o processo produtivo foi otimizado e as filas de espera e o lead-time foram reduzidos, melhorando o atendimento aos clientes.

\section{Palavras-chave}

Programação linear inteira. Método simulação-otimização. Cilindros de laminação. Produção não seriada.

\section{Introdução}

0 cenário atual de intensa competitividade entre as cadeias de suprimento ultrapassa a competição pura e simples entre as empresas, levando-as a reexaminar suas estratégias de gerenciamento de materiais, sistemas e métodos de produção.

Oliveira, Duarte e Montevechi (2002) afirmam que a produção tem o desafio de desenvolver novas metodologias ou adotar sistemas de gestão que possibilitem a sobrevivência da empresa no mercado. Tais sistemas exigem uma reestruturação organizacional que permita alcançar os objetivos propostos.

Ao longo das últimas décadas, percebe-se o estreitamento do relacionamento entre a média e a alta gerência, embora a busca pela integração entre estratégia e manufatura ainda esteja presente e válida.

Papadopoulos, Heavey e Browne (1993) comentam que uma empresa de manufatura costuma lidar com problemas de tomada de decisão no âmbito estratégico, tático e operacional. No nível estratégico estão as decisões relacionadas à missão da empresa e a seus objetivos de longo prazo, tais como: localização de plantas industriais, aquisição de novos recursos e introdução de novas tecnologias e produtos. As decisões de nível tático situam-se em um horizonte de planejamento mais estreito, que varia de semanas a meses, e servem, geralmente, de input para as decisões de longo prazo. Essas decisões estão relacionadas ao tipo de sistema de fabricação (produção em massa ou em lotes), ao modelo de produto a ser fabricado e ao volume a ser produzido. Finalmente, as decisões de nível operacional, tomadas no ambiente do chão de fábrica, são aquelas de curto prazo, podendo variar de horas até dias e, geralmente, estão relacionadas à alocação dos recursos recuperáveis (máquinas) para a transformação dos recursos irrecuperáveis (matérias-primas e componentes) em produtos acabados.

0 propósito do presente trabalho foi elaborar um modelo de planejamento e gestão da produção, utilizando a técnica de programação linear inteira (PLI), e avaliar, por meio de um modelo de simulação, as interferências que possam ocorrer durante o processo 
de fabricação de um cilindro de laminação. Além disso, por meio da simulação, objetivou-se otimizar a gestão do equipamento gargalo de forma a estabelecer prioridades de usinagem e transformar o processo num fluxo contínuo, sem desabastecimento das linhas.

\section{Modelagem}

A pesquisa operacional (P0) é um método científico de trabalho que auxilia o processo de decisão e visa obter o melhor rendimento possível no funcionamento de uma organização ou sistema em estudo. Para isso, utiliza técnicas e instrumentos científicos, baseando-se em análises quantitativas, e seu objetivo é descobrir regularidade em algum fenômeno e correlacionar essa regularidade a outros conhecimentos, de tal forma que o fenômeno possa ser modificado ou controlado (HILLIER; LIEBERMAN, 2006; LACHTERMACHER, 2004; ARENALES et al., 2007). A modelagem aqui descrita utiliza a programação linear inteira e a simulação de sistemas.

\subsection{Simulação-otimização}

Desde a metade do século passado, analistas da PO vêm desenvolvendo um grande conjunto de técnicas e conhecimentos para solucionar os problemas que aparecem em muitos sistemas complexos (GRANGER; KRISHNAMURTHY; ROBINSON, 2002).

Entretanto, a complexidade dos sistemas atuais impede que aproximações analíticas tradicionais isoladas levem a soluções completamente satisfatórias (KÖCHEL; KUNZE; NIELÄNDER, 2003). Nesse ambiente surgiu a simulação-otimização (Figura 1), que integra um simulador de sistema real a métodos de otimização satisfatórios para um determinado problema, associando os objetivos da otimização às vantagens da simulação (CECILIANO, 2007; PINTO JUNIOR, 2001).

Azadivar (1999) definiu um problema de simulação-otimização como um problema de otimização em que a função-objetivo e/ou algumas restrições são avaliadas por meio da simulação computacional.

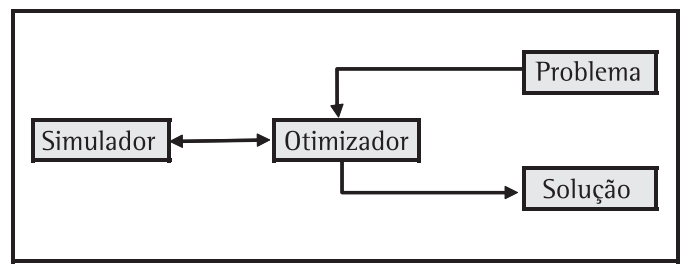

Figura 1. Princípio da simulação-otimização. Fonte: Köchel, Kunze e Nieländer, (2003).
O desenvolvimento de métodos de simulação-otimização é, atualmente, um campo ativo de pesquisa. Além disso, a elaboração de modelos que utilizam os conceitos de simulação e otimização simultaneamente tem se tornado cada vez mais frequente (CECILIANO, 2007; PINTO JUNIOR, 2001).

A simulação, geralmente, tem como foco a estimativa de desempenho, enquanto a análise matemática sempre envolve o cálculo analítico do desempenho do sistema (CARDOSO; VINHOZA; SAMPAIO NETO, 2007).

Morito et al. (1999) afirmam que as forças e fraquezas da programação matemática (PM) e da simulação são complementares. Enquanto a PM é fraca em pontos como desconhecimento da relação de entrada/saída, dinamismo do sistema, não linearidade, ausência de aleatoriedade e detalhes dos sistemas, a simulação é fraca em sua capacidade de otimização (MORITO et al., 1999; CECILIANO, 2007).

Embora alguns problemas importantes sejam de natureza da otimização, sua aplicação para problemas complexos pode conduzir a dificuldades de interpretação dos resultados. Uma vez que em certas situações não é possível incluir todas as restrições e procedimentos operacionais de um sistema real em um modelo de otimização, a simulação pode ser uma ferramenta útil para incorporar todos estes aspectos (CECILIANO, 2007).

Já para utilizar-se a simulação na avaliação e na melhoria do desempenho de um processo é necessário construir cenários, executá-la para cada cenário e, em seguida, analisar os resultados. lsso, apesar da capacidade de gerar bons resultados, pode se tornar muito cansativo e consumir muito tempo; além de não garantir que as melhores configurações sejam experimentadas (PINHO, 2008).

0 intuito de associar as técnicas de otimização e simulação é justamente resolver tais problemas. Uma característica comum aos métodos de simulação-otimização é a representação dos parâmetros de decisão do sistema por meio de funções implícitas, e a natureza estocástica da função-objetivo e/ou das restrições do problema, que podem ser avaliadas por meio de simulação (AZADIVAR, 1999).

Outra característica comum aos métodos de simulação-otimização convencionais é a simulação repetitiva do sistema: a cada passo de melhoria, o desempenho do sistema é avaliado, ao menos uma vez, pela simulação (GRANGER; KRISHNAMURTHY; ROBINSON, 2002). 0 analista simula um sistema específico e determina o valor ótimo para algum parâmetro dentro do problema, mediante a aplicação de uma técnica de otimização. A seguir, o analista aplica a simulação aos resultados do problema de 
otimização para conferir a validade dos mesmos, utilizando os resultados do modelo de otimização como inputs para o modelo de simulação. Caso a solução não seja considerada satisfatória, a otimização deverá gerar, baseada nos resultados da etapa anterior, uma nova solução, que deverá ser testada novamente pela simulação. Esse ciclo é repetido até que algum critério de parada seja satisfeito (FU, 2002; BUSH; BILES; DEPUY, 2003).

De acordo com Azadivar (1999), as principais vantagens da simulação-otimização, são:

- A complexidade do sistema modelado não afeta significativamente o desempenho do processo de otimização;

- Para sistemas estocásticos, a variabilidade da resposta pode ser controlada por meio de várias técnicas de análise de dados de saída;

- 0 modelo de simulação permite a inclusão de detalhes (procedimentos operacionais e restrições complexas) que não podem ser considerados num modelo de otimização convencional (BUSH; BILES; DEPUY, 2003);

- A presença da simulação fornece uma vantagem que não é frequentemente possível em procedimentos clássicos de otimização: mediante o emprego de técnicas apropriadas, a função-objetivo e/ou as restrições podem ser modificadas de uma interação para outra para refletir as possíveis alternativas do sistema em estudo; e

- Os resultados oriundos do modelo de otimização podem ser validados por um modelo de simulação. Nesse caso, como os resultados e parâmetros do modelo de otimização serão usados como entradas do modelo de simulação, é possível comparar os resultados da simulação com soluções consideradas aceitáveis para o sistema real, permitindo ao analista modificar o modelo de otimização se tais resultados não forem aceitáveis. Dessa forma, a técnica de simulação-otimização garante que as soluções encontradas sejam viáveis para o sistema real e não apenas para o modelo de otimização (BUSH; BILES; DEPUY, 2003).

Azadivar (1999) relata, ainda, que as principais desvantagens da simulação-otimização são:

- Não há uma expressão analítica da função-objetivo ou das restrições, o que elimina a possibilidade de diferenciação ou cálculo exato de gradientes locais;

- A função-objetivo e as restrições são funções estocásticas de variáveis de decisão determinísticas. Isso representa um grande problema até mesmo na estimativa de derivadas locais aproximadas. Além disso, causa problemas até mesmo usando enumeração completa, uma vez que, baseada em uma só observação de cada ponto, não se pode determinar o melhor ponto de decisão;
- A simulação computacional é muito mais custosa do que a avaliação de funções analíticas. Isso torna crítica a eficiência dos algoritmos de otimização; e

- As linguagens de simulação são bastante diferentes das linguagens de otimização. Fazer a interface dos modelos de simulação com modelos genéricos de otimização nem sempre é uma tarefa fácil, especialmente quando se trata das modernas linguagens de simulação de alto nível.

\section{Método de pesquisa}

A Figura 2 exibe o fluxograma com o método utilizado para desenvolver este trabalho.

0 mapeamento de processos facilitou a visualização e compreensão das atividades executadas no processo e suas interrelações. Já a identificação do gargalo

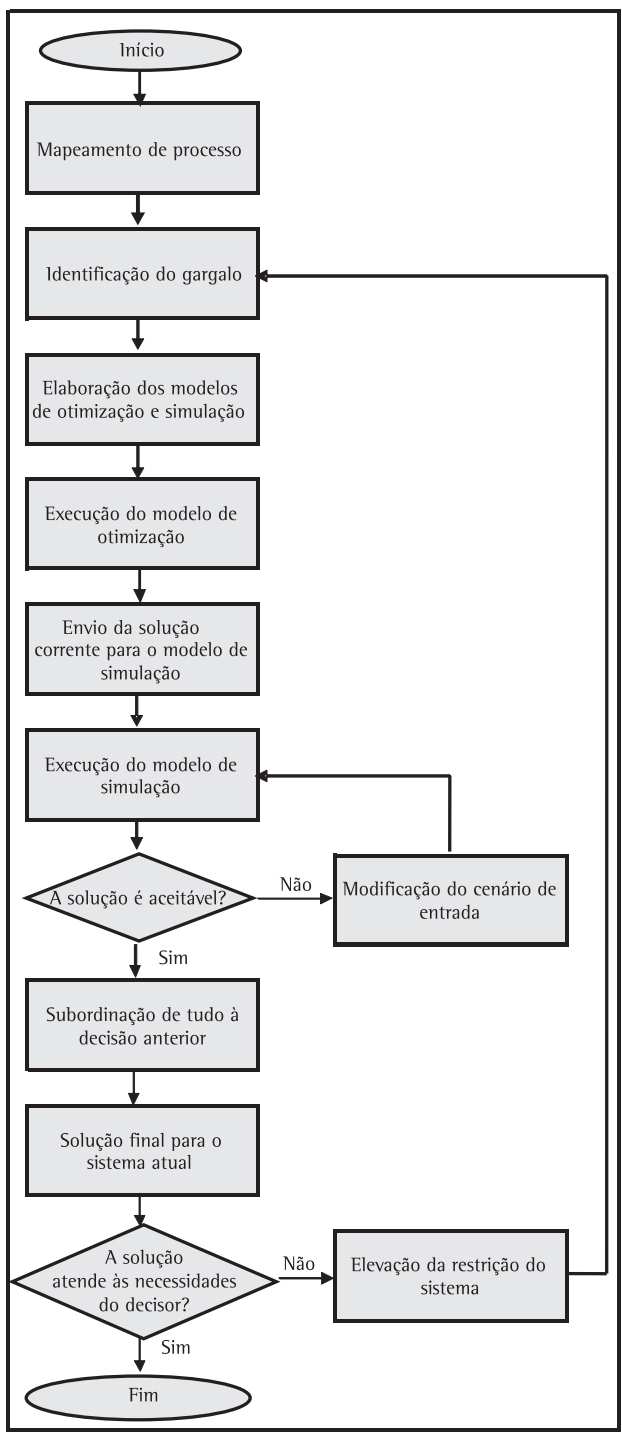

Figura 2. Etapas do método de pesquisa. 
direcionou e concentrou os esforços nos pontos cruciais do sistema analisado. 0 modelo de PLl adotado, e resolvido pelo Solver ${ }^{\circledR}$, considerou apenas fatores essenciais do problema, enquanto os detalhes foram incluídos no modelo de simulação. A validação do modelo matemático foi realizada por avaliação dos resultados obtidos com o modelo e por comparação destes resultados com os resultados obtidos no sistema real.

Com respeito ao modelo de simulação desenvolvido, foi utilizado um procedimento adaptado daqueles propostos por Bateman e Bowden (2002), Chwif e Medina (2006) e Fernandes (2008), conforme Figura 3 e descrito a seguir.

Definição do problema e dos objetivos: Um sistema pressupõe uma interação de causa-efeito entre os elementos que o compõem. Para que tais elementos e para que as interações entre eles possam ser identificados, o objetivo do sistema deve ser estabelecido com clareza (CHIWIF; MEDINA, 2006).

Uma vez entendido o processo, é necessário definir claramente o problema, as perguntas a serem respondidas, as hipóteses a serem testadas e os efeitos a serem estimados, garantindo que o problema esteja completamente entendido e que exista uma solução técnica para resolvê-lo (CHIWIF; MEDINA, 2006).

Os objetivos de um estudo de simulação fluirão naturalmente a partir da definição do problema, uma vez que o propósito da experimentação é resolver esse problema (BATEMAN; BOWDEN, 2002).
Formulação e planejamento do modelo: Uma vez determinados o problema e os objetivos da simulação, definem-se os cenários alternativos que serão considerados, como cada cenário será avaliado e os dados necessários. Deve-se, também, especificar a abrangência do modelo, os recursos necessários (orçamento, equipamentos etc.) e o cronograma de atividades (PEIXOTO, 2006). Além disso, o analista poderá desenvolver, nessa etapa, uma estrutura conceitual para o modelo, que deverá incluir, via de regra, eventos e elementos fundamentais (BATEMAN; BOWDEN, 2002).

Assim, é necessário identificar e incluir apenas aqueles fatores que apresentem impacto significativo no comportamento do modelo, que devem estar em conformidade com o propósito da simulação (BATEMAN; BOWDEN, 2002).

Coleta e tratamento de dados: A coleta se refere a dados quantitativos e qualitativos sobre as entradas e saídas do sistema, assim como a informações sobre seus componentes e relações (GAVIRA, 2003).

Dessa forma, a etapa de coleta de dados tem início com a escolha adequada das variáveis de entrada do sistema a ser simulado, cabendo ao analista definir os dados necessários (GAVIRA, 2003; CHWIF; MEDINA, 2006). A ênfase inicial deve ser a coleta de fatos fundamentais, informações e estatísticas que algumas vezes se referem a dados de âmbito global. Isso vai permitir ao analista solicitar informações mais detalhadas de outros participantes, reunindo dados que serão necessários em estágios posteriores

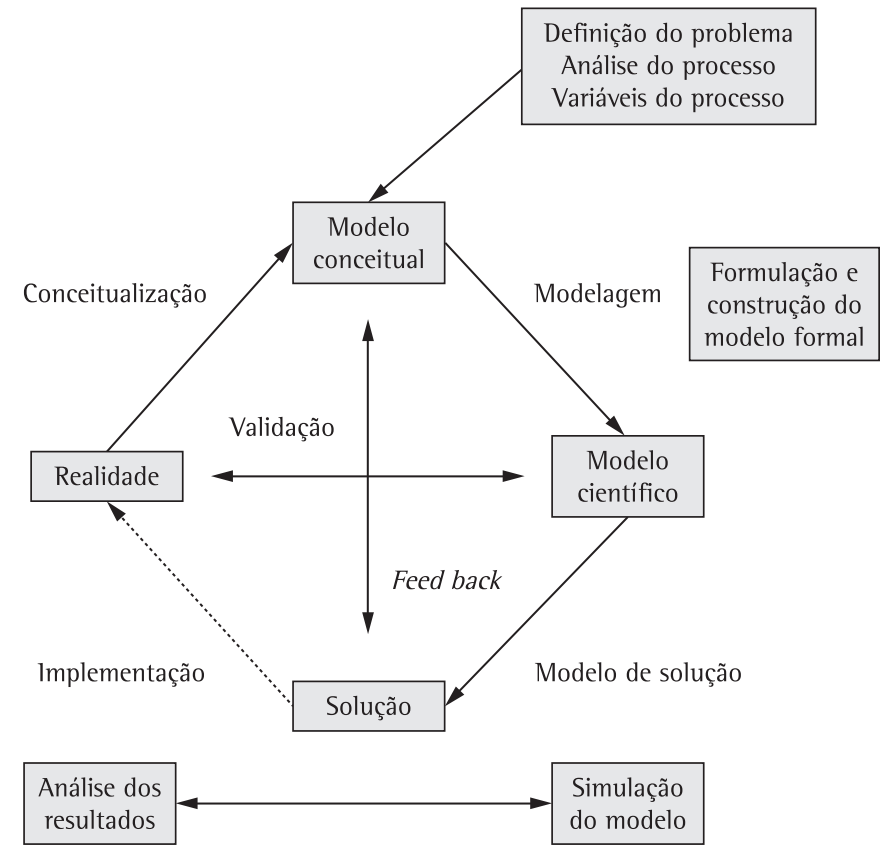

Figura 3. Desenvolvimento de um modelo de simulação. Fonte: Fernandes (2008). 
do projeto (BATEMAN; BOWDEN, 2002; CHWIF; MEDINA, 2006).

Os dados utilizados neste trabalho estavam disponíveis no sistema da empresa - ERP (Enterprise Resource Planning) e que eram mantidos atualizados pelos setores de engenharia de processo e de produto.

Desenvolvimento do modelo: Todos os modelos de simulação são desenvolvidos para representar algum tipo de sistema. Basicamente, os componentes de um sistema são as entidades dinâmicas, os recursos e as filas (PAIVA, 2005; PEIXOTO, 2006).

Entidades dinâmicas são os objetos que se movem através do sistema e que necessitam dos serviços e/ou processamento de alguns dos recursos do sistema. Entidades têm atributos que descrevem suas características e passam por eventos, que são ocorrências instantâneas que podem alterar o estado do sistema ou de seus atributos.

Recursos são as entidades estáticas que promovem o serviço ou processam uma entidade, podendo ser máquinas, pessoas, correias transportadoras etc. Os recursos estão relacionados a atividades que demandam um período de tempo especificado.

As filas, por sua vez, constituem locais de espera onde as entidades dinâmicas aguardam a sua vez de seguir através do sistema.

De acordo com Cardoso, Vinhoza e Sampaio Neto (2007), um modelo de simulação nada mais é do que um diagrama em blocos que descreve a interconexão dos vários subsistemas componentes, sendo, cada bloco, constituído por uma expressão matemática, ou conjunto de equações que definem o relacionamento entre entrada e saída.

Para Balci (1997), o modelo conceitual pode ser utilizado como uma ferramenta de controle do processo de modelagem e simulação, podendo auxiliar na avaliação de conceitos, eficácia e erros, além de servir como base para o projeto de modelagem e simulação, e de auxiliar no processo de verificação e validação do modelo computacional.

Criar um modelo formal ou conceitual nada mais é do que representar um sistema real num diagrama de fluxo lógico. 0 diagrama representará o problema por meio de associações feitas entre as entidades e as atividades.

Verificação: A etapa de verificação está relacionada ao modo como o modelo está sendo implementado e consiste na eliminação dos erros do modelo computacional (CHWIF; MEDINA, 2006).

Um modelo estará pronto para ser verificado quando funcionar da maneira como o analista pretendia. Para a verificação do modelo aqui apresentado, foram utilizadas as animações, os contadores e o depurador que acompanham o software onde o modelo foi implementado.

Validação: Está ligada ao modelo conceitual e relacionada ao que foi modelado (CHWIF; MEDINA, 2006). A validação é o processo de assegurar que o modelo criado reflete com fidelidade a operação do sistema real em estudo (respeitando-se um intervalo de aceitação para as variáveis analisadas), de tal forma que dê encaminhamento ao problema definido (CHWIF; MEDINA, 2006; MONTEVECHI et al., 2002).

Uma técnica utilizada para validar um modelo de simulação consiste em escolher uma pessoa que entenda bem do sistema (especialista) que foi simulado e apresentar a ela dois conjuntos de dados de saída, um proveniente do sistema real e outro do modelo de simulação. Se o especialista não conseguir distinguir se os resultados são oriundos do sistema real ou do modelo de simulação, então o modelo é considerado "válido".

Outro método empregado para testar um modelo consiste em realizar alterações nos dados de entrada e verificar se o mesmo responde às mudanças da mesma forma que o sistema real. Alterando o valor de um parâmetro de entrada e comparando o impacto com as respostas conhecidas do sistema, é possível estabelecer a credibilidade de um modelo. Os resultados desse tipo de teste servirão também como análise de sensibilidade para identificar os tipos de informação que merecem esforço adicional de conjunção de dados.

Ainda, outra forma de validação estabelece o uso de dados de entrada históricos para alimentar o modelo. As saídas do modelo devem ser então comparadas com as saídas históricas para se determinar se o modelo consegue reproduzir satisfatoriamente 0 comportamento do sistema real (BATEMAN; BOWDEN, 2002; CHWIF; MEDINA, 2006).

Embora para efeito didático a validação e a verificação do modelo tenham sido apresentadas neste trabalho após a construção do modelo computacional, essas devem acompanhar todas as etapas do projeto na forma de um processo contínuo.

0 modelo criado neste trabalho foi validado por meio da utilização de dados históricos e da comparação das saídas do modelo com resultados reais.

Experimentação: Consiste no desenvolvimento de procedimentos e testes para analisar e comparar alternativas, maximizando a utilidade da informação produzida pela execução da simulação (BATEMAN; BOWDEN, 2002).

0 ideal é que o analista e demais envolvidos no projeto tenham ideias preliminares sobre as alternativas de solução a avaliar.

Uma das preocupações do analista nesta etapa do processo é determinar o momento em que o 
modelo passa a atuar em regime permanente, pois durante o regime transitório o desempenho do sistema relaciona-se fortemente as suas condições iniciais. Dessa forma, o regime transitório, além de ser mais complexo e pouco conclusivo, pode afetar perigosamente os resultados de uma simulação, uma vez que as condições iniciais do sistema nem sempre são as mesmas (CHWIF; MEDINA, 2006).

Diversas simulações compostas de $n$ replicações para valores diferentes de warm-up devem ser feitas para determinar o período de aquecimento. 0 comportamento da variável de resposta é monitorado ao longo das simulações. Quando essa variável se estabiliza em torno de um determinado valor, o período de aquecimento é obtido com o acréscimo de um fator de segurança de $20 \%$ a $30 \%$ em relação ao valor em que teve início a estabilização da variável de resposta, conforme Chwif e Medina (2006).

0 analista irá, então, considerar a variação dos resultados de saída e determinar o número de replicações necessárias para obter uma amostragem estatística confiável (BATEMAN; BOWDEN, 2002).

0 intervalo de confiança (COSTA NETO, 2002) para a média da variável do sistema, para desvio padrão conhecido, é dado pela Equação 1:

$P\left[\overline{\bar{X}}\left(1-\frac{r}{100}\right) \leq \mu \leq \overline{\bar{X}}\left(1+\frac{r}{100}\right)\right]=1-\alpha$

onde, $\overline{\bar{X}}$ é o valor inicialmente estimado para a média amostral $\bar{X}$; $r$ é a precisão desejada (em \%); $\sigma$ é o desvio padrão (conhecido); $n$ é o tamanho da amostra de resultados da variável de interesse, dado por $n=\left(\frac{100 \cdot Z_{\alpha} / 2}{r \cdot \overline{\bar{X}}}\right)^{2} ; \alpha$ é o nível de confiança e $Z$ é uma variável aleatória com distribuição $\operatorname{Normal}(0,1)$.

No caso de desvio padrão desconhecido, tem-se a Equação 2, onde se utiliza o desvio padrão amostral (s) e substitui-se a distribuição Normal pela distribuição t-Student:

$n=\left(\frac{100 \cdot t_{n-1, \alpha / 2} \cdot s}{r . \bar{X}}\right)^{2}$

Utiliza-se a Equação 2 para determinar o número de replicações. Para isso, é necessário estimar, inicialmente, um valor para a média amostral e definir a precisão e a confiança estatística desejadas, obtendo-se, então, um primeiro valor para $n$. A seguir, realiza-se uma simulação com o número de replicações encontrado. Calcula-se, então, o valor médio da variável resposta fornecido pelo modelo computacional e compara-se esse valor com o valor estimado anteriormente. Se o valor encontrado com a simulação for maior ou igual ao que foi admitido anteriormente, o valor de $n$ obtido na Equação 2 será o número de replicações a ser utilizado no modelo computacional. Caso contrário, deve-se recalcular o valor de $n$, utilizando-se a média da variável resposta obtida com a simulação como estimativa para o novo valor da média amostral e repetir o processo (COSTA NETO, 2002).

Análise dos resultados e apresentação: A fim de selecionar a alternativa testada que apresentou melhor desempenho, o analista deve realizar uma análise estatística dos resultados.

Cada configuração do modelo e seus respectivos resultados de saída devem ser documentados. Além de facilitar relatos eventuais, o armazenamento dos registros poderá auxiliar o modelador/analista a determinar a alternativa que atinge melhor resultado e permitirá a ele observar tendências que possam sugerir alternativas adicionais a considerar (BATEMAN; BOWDEN, 2002).

Para comprovar a melhoria no sistema real utilizando a simulação, deve-se realizar a comparação entre as médias antes e após a implementação do modelo, por meio do teste de hipótese. Aqui foi utilizado o método de Aspin-Welch (COSTA NETO, 2002) para comparar as duas médias. Esse método sugere tomar o $t$ crítico com número de graus de liberdade dado pela Equação 3:

$$
v=\frac{\left(w_{1}+w_{2}\right)^{2}}{\frac{w_{1}^{2}}{\left(n_{1}+1\right)}+\frac{w_{2}^{2}}{\left(n_{2}+1\right)}}-2
$$

onde $w_{1}=\frac{s_{1}^{2}}{n_{1}}$ e $w_{2}=\frac{s_{2}^{2}}{n_{2}}$

$$
t_{\text {calculado }}=\frac{\left(\overline{x_{1}}-\overline{x_{2}}\right)}{\sqrt{\frac{s_{1}^{2}}{n_{1}}+\frac{s_{2}^{2}}{n_{2}}}}
$$

Implementação: Esta etapa começa com o projeto de simulação e termina com os ajustes finais do modelo, a preparação e formação do pessoal que irá utilizá-lo no dia a dia e com a garantia da validade dos resultados (PAIVA, 2005).

0 sucesso dessa etapa depende do bom desenvolvimento de todas as fases anteriores. Se todos aqueles que forem abrangidos pelo processo se mantiverem informados e envolvidos em todas as etapas, eles estarão muito mais dispostos a auxiliar na implementação da solução selecionada (BATEMAN; BOWDEN, 2002).

Como o modelo de PLl desenvolvido neste trabalho considera apenas fatores essenciais do sistema, ele 
não é capaz, por si só, de avaliar as interferências que podem ocorrer durante o processo produtivo. Assim, a etapa seguinte do método proposto consiste em enviar os resultados obtidos no modelo de otimização para o modelo de simulação, uma vez que esse último contempla mais detalhes do sistema analisado.

Para isso, o analista deve determinar quais cenários deverão ser avaliados, para, a seguir, executar o modelo de simulação (com as devidas replicações) e complementar a solução obtida pelo modelo de otimização. Após a execução do modelo, o analista deve avaliar os resultados e decidir se a solução obtida é aceitável ou não.

Caso a solução não seja considerada aceitável, o analista deve escolher outro cenário e realizar uma nova simulação, até que uma solução satisfatória seja encontrada.

As necessidades das restrições é que determinarão o programa de produção das não restrições. Assim, depois de definir como explorar as restrições do sistema, os recursos não limitadores (não restrição) devem ser subordinados às restrições do sistema. Após a execução desse passo, chega-se à solução final para o atual sistema, que deve ser implantada na linha de produção.

\section{Estudo de caso}

A empresa foco do estudo de caso é uma siderúrgica, situada em Pindamonhangaba, SP. É uma das três maiores produtoras de cilindros de laminação do mundo e tem como missão ser referência no mercado mundial. Sua carteira de clientes é formada por empresas siderúrgicas e sua produção atual é de, aproximadamente, 40.000 t/ano, das quais $80 \%$ são destinados ao mercado internacional.

Nos últimos anos, devido ao crescimento da produção no mercado externo, o atendimento ao prazo tornou-se um dos fatores preponderantes para o sucesso da empresa.

0 acompanhamento do desempenho de embarque é realizado mensalmente conforme a Tabela 1. Com o aumento das exportações, percebeu-se a dificuldade de cumprimento do prazo interno de liberação do produto (data de liberação interna do produto é chamada de "data de remessa"), impedindo a exportação do produto na data acordada, e, por consequência, atraso na entrega do produto ao cliente final.

Para verificar o comportamento de acerto da data de remessa, foi realizado um levantamento comparando a data de remessa real e a data de remessa prevista (acerto). A Figura 4 mostra o acerto em relação à data de remessa prevista. Observa-se que o acerto

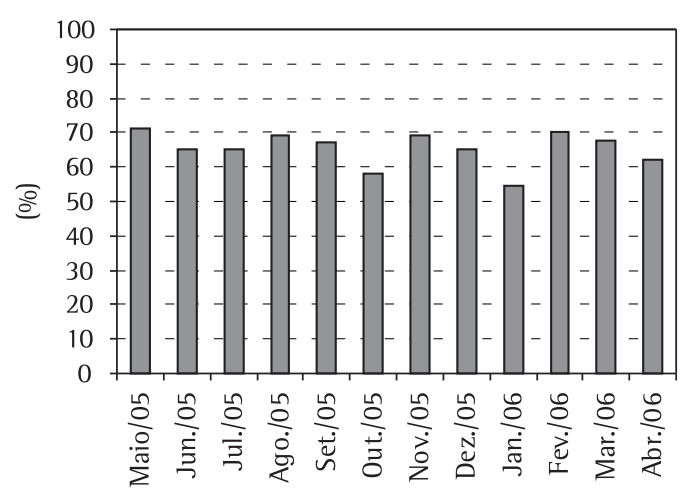

Figura 4. Acerto da data de remessa - previsto $\times$ real.

entre a data de remessa prevista e a real se mantinha entre 60\% e 70\%.

Esse levantamento mostrou problemas no atendimento da data de remessa prevista, gerando reprogramações de embarque que podem causar atrasos na entrega ao cliente. A fim de identificar o principal fator de influência nesse atraso, analisou-se a linha de processo da produção.

\subsection{Linha de produção}

A Figura 5 expõe uma representação esquemática do processo de produção de um cilindro forjado.

0 sistema de produção de cilindros de laminação de tiras a frio pode ser dividido basicamente em três setores: lingotamento, forjaria e usinagem e tratamento térmico (UTT).

Os cilindros são lingotados e enviados para a Forjaria, onde são prensados com a finalidade de obter-se produtos semiacabados; em seguida, os semiacabados são encaminhados para o setor de usinagem e tratamento térmico. No setor de lingotamento, o aço líquido proveniente da aciaria é transportado numa panela com capacidade máxima de 90 t de metal líquido. Entretanto, como há perdas metálicas no processo (exemplo: formação de escória, perdas nos canais que alimentam as lingoteiras etc.), a capacidade líquida que é disponibilizada para a produção é de $86 \mathrm{t}$ de metal.

Após o lingotamento, aguarda-se a solidificação dos lingotes. Uma vez solidificados, os "cilindros" são retirados das lingoteiras e colocados num vagão, o qual os encaminhará para a Forjaria, onde serão colocados em fornos de aquecimento até passarem pela prensa. Depois do processo de forjamento, os cilindros são enviados para fornos de tratamento térmico antes de serem enviados para a UTT.

Depois de passar pela Forjaria, os cilindros são encaminhados para o setor de usinagem e tratamento 
Fernandes, L. J. et al.

Planejamento e controle da ... estudo de caso quantitativo. Produção, v. 23, n. 1, p. 120-135, jan./mar. 2013

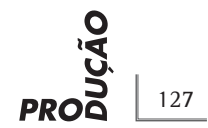

Tabela 1. Acompanhamento dos embarques.

\begin{tabular}{|c|c|c|c|c|c|c|c|c|c|c|c|}
\hline OV & Cliente & Cil. & Liga & Peso & $\begin{array}{l}\text { Prev. } \\
\text { remessa }\end{array}$ & $\begin{array}{c}\text { Rev. } \\
\text { remessa }\end{array}$ & $\begin{array}{l}\text { Prev. } \\
\text { emb. }\end{array}$ & Rev. emb. & $\begin{array}{l}\text { Efet. } \\
\text { emb. }\end{array}$ & Porto & Navio \\
\hline 412165 & A & 56756 & 1 & 6360 & $27 / 10 / 06$ & $30 / 10 / 06$ & $05 / 11 / 06$ & $13 / 11 / 06$ & $13 / 11 / 06$ & Tampico & $\begin{array}{c}\text { Cap } \\
\text { Polonio }\end{array}$ \\
\hline 412165 & A & 56757 & 1 & 6360 & $27 / 10 / 06$ & $30 / 10 / 06$ & $05 / 11 / 06$ & $13 / 11 / 06$ & $13 / 11 / 06$ & Tampico & $\begin{array}{c}\text { Cap } \\
\text { Polonio }\end{array}$ \\
\hline 412165 & A & 56758 & 1 & 6360 & $27 / 10 / 06$ & $30 / 10 / 06$ & $05 / 11 / 06$ & $13 / 11 / 06$ & $13 / 11 / 06$ & Tampico & $\begin{array}{c}\text { Cap } \\
\text { Polonio }\end{array}$ \\
\hline 412165 & A & 56759 & 1 & 6360 & $30 / 10 / 06$ & $01 / 11 / 06$ & $05 / 11 / 06$ & $13 / 11 / 06$ & $13 / 11 / 06$ & Tampico & $\begin{array}{c}\text { Cap } \\
\text { Polonio }\end{array}$ \\
\hline 412165 & A & 56760 & 1 & 6360 & $30 / 10 / 06$ & $01 / 11 / 06$ & $05 / 11 / 06$ & $13 / 11 / 06$ & $13 / 11 / 06$ & Tampico & $\begin{array}{c}\text { Cap } \\
\text { Polonio }\end{array}$ \\
\hline 412165 & A & 56761 & 1 & 6360 & $30 / 10 / 06$ & $01 / 11 / 06$ & $05 / 11 / 06$ & $13 / 11 / 06$ & $13 / 11 / 06$ & Tampico & $\begin{array}{c}\text { Cap } \\
\text { Polonio }\end{array}$ \\
\hline 412333 & B & 58030 & 2 & 1395 & $29 / 10 / 06$ & & $07 / 11 / 06$ & & $07 / 11 / 06$ & Callao & $\begin{array}{c}\text { Aliança } \\
\text { Andes }\end{array}$ \\
\hline 412333 & B & 58031 & 2 & 1395 & 29/10/06 & & $07 / 11 / 06$ & & $07 / 11 / 06$ & Callao & $\begin{array}{c}\text { Aliança } \\
\text { Andes }\end{array}$ \\
\hline 412333 & B & 58032 & 2 & 1395 & $29 / 10 / 06$ & & $07 / 11 / 06$ & & $07 / 11 / 06$ & Callao & $\begin{array}{c}\text { Aliança } \\
\text { Andes }\end{array}$ \\
\hline 412333 & $\mathrm{~B}$ & 58033 & 2 & 1395 & $30 / 10 / 06$ & & $07 / 11 / 06$ & & $07 / 11 / 06$ & Callao & $\begin{array}{c}\text { Aliança } \\
\text { Andes }\end{array}$ \\
\hline 412333 & B & 58034 & 2 & 1395 & $30 / 10 / 06$ & & $07 / 11 / 06$ & & $07 / 11 / 06$ & Callao & $\begin{array}{l}\text { Aliança } \\
\text { Andes }\end{array}$ \\
\hline 412333 & $\mathrm{~B}$ & 58035 & 2 & 1395 & $30 / 10 / 06$ & & $07 / 11 / 06$ & & $07 / 11 / 06$ & Callao & $\begin{array}{c}\text { Aliança } \\
\text { Andes }\end{array}$ \\
\hline 412333 & B & 58036 & 2 & 1395 & $30 / 10 / 06$ & & $07 / 11 / 06$ & & $07 / 11 / 06$ & Callao & $\begin{array}{c}\text { Aliança } \\
\text { Andes }\end{array}$ \\
\hline 412341 & B & 58112 & 2 & 800 & $22 / 10 / 06$ & & $07 / 11 / 06$ & & $07 / 11 / 06$ & Callao & $\begin{array}{c}\text { Aliança } \\
\text { Andes }\end{array}$ \\
\hline 412341 & B & 58113 & 2 & 800 & $22 / 10 / 06$ & & $07 / 11 / 06$ & & $07 / 11 / 06$ & Callao & $\begin{array}{c}\text { Aliança } \\
\text { Andes }\end{array}$ \\
\hline 412341 & $\mathrm{~B}$ & 58114 & 2 & 800 & $22 / 10 / 06$ & & $07 / 11 / 06$ & & $07 / 11 / 06$ & Callao & $\begin{array}{c}\text { Aliança } \\
\text { Andes }\end{array}$ \\
\hline 412341 & B & 58115 & 2 & 800 & $27 / 10 / 06$ & & $07 / 11 / 06$ & & $07 / 11 / 06$ & Callao & $\begin{array}{c}\text { Aliança } \\
\text { Andes }\end{array}$ \\
\hline 411882 & C & 54106 & 1 & 11756 & $23 / 10 / 06$ & & $01 / 11 / 06$ & & $02 / 11 / 06$ & Xingang & $\begin{array}{c}\text { Clan lntre } \\
\text { Pid }\end{array}$ \\
\hline 411882 & C & 54107 & 1 & 11756 & $22 / 10 / 06$ & & $01 / 11 / 06$ & & $02 / 11 / 06$ & Xingang & $\begin{array}{c}\text { Clan Intre } \\
\text { Pid }\end{array}$ \\
\hline 411882 & C & 54108 & 1 & 11756 & $24 / 10 / 06$ & & $01 / 11 / 06$ & & $02 / 11 / 06$ & Xingang & $\begin{array}{c}\text { Clan Intre } \\
\text { Pid }\end{array}$ \\
\hline 411882 & C & 54109 & 1 & 11756 & $24 / 10 / 06$ & & $01 / 11 / 06$ & & $02 / 11 / 06$ & Xingang & $\begin{array}{c}\text { Clan Intre } \\
\text { Pid }\end{array}$ \\
\hline 412059 & $\mathrm{D}$ & 55938 & 3 & 745 & 08/10/06 & & $18 / 11 / 06$ & & $20 / 11 / 06$ & $\begin{array}{l}\text { Puerto } \\
\text { Limon }\end{array}$ & $\begin{array}{c}\text { Cap } \\
\text { Blanco }\end{array}$ \\
\hline 412077 & $\mathrm{D}$ & 55997 & 2 & 1349 & 08/10/06 & & 18/11/06 & & $20 / 11 / 06$ & $\begin{array}{l}\text { Puerto } \\
\text { Limon }\end{array}$ & $\begin{array}{c}\text { Cap } \\
\text { blanco }\end{array}$ \\
\hline 412083 & D & 56010 & 2 & 1788 & 08/10/06 & & $18 / 11 / 06$ & & $20 / 11 / 06$ & $\begin{array}{l}\text { Puerto } \\
\text { Limon }\end{array}$ & $\begin{array}{c}\text { Cap } \\
\text { Blanco }\end{array}$ \\
\hline 412083 & $\mathrm{D}$ & 56011 & 2 & 1788 & 08/10/06 & & $18 / 11 / 06$ & & $20 / 11 / 06$ & $\begin{array}{l}\text { Puerto } \\
\text { Limon }\end{array}$ & $\begin{array}{c}\text { Cap } \\
\text { Blanco }\end{array}$ \\
\hline 412084 & D & 56012 & 3 & 1869 & $30 / 10 / 06$ & & $18 / 11 / 06$ & & $20 / 11 / 06$ & $\begin{array}{l}\text { Puerto } \\
\text { Limon }\end{array}$ & $\begin{array}{c}\text { Cap } \\
\text { Blanco }\end{array}$ \\
\hline 412168 & $\mathrm{E}$ & 56857 & 3 & 1536 & $26 / 10 / 06$ & & 09/11/06 & & $08 / 11 / 06$ & Cartagena & $\begin{array}{l}\text { Cala Porto } \\
\text { Fino }\end{array}$ \\
\hline 412345 & $\mathrm{E}$ & 58146 & 2 & 625 & $18 / 10 / 06$ & & 09/11/06 & & $08 / 11 / 06$ & Cartagena & $\begin{array}{l}\text { Cala Porto } \\
\text { Fino }\end{array}$ \\
\hline 412345 & $\mathrm{E}$ & 58147 & 2 & 625 & 18/10/06 & & 09/11/06 & & $08 / 11 / 06$ & Cartagena & $\begin{array}{l}\text { Cala Porto } \\
\text { Fino }\end{array}$ \\
\hline 412346 & $\mathrm{E}$ & 58148 & 2 & 625 & $22 / 10 / 06$ & & 09/11/06 & & $08 / 11 / 06$ & Cartagena & $\begin{array}{l}\text { Cala Porto } \\
\text { Fino }\end{array}$ \\
\hline 412346 & $E$ & 58149 & 2 & 625 & $22 / 10 / 06$ & & 09/11/06 & & $08 / 11 / 06$ & Cartagena & $\begin{array}{l}\text { Cala Porto } \\
\text { Fino }\end{array}$ \\
\hline 412347 & $\mathrm{E}$ & 58150 & 2 & 625 & 29/10/06 & & $09 / 11 / 06$ & & $08 / 11 / 06$ & Cartagena & $\begin{array}{c}\text { Cala Porto } \\
\text { Fino }\end{array}$ \\
\hline
\end{tabular}




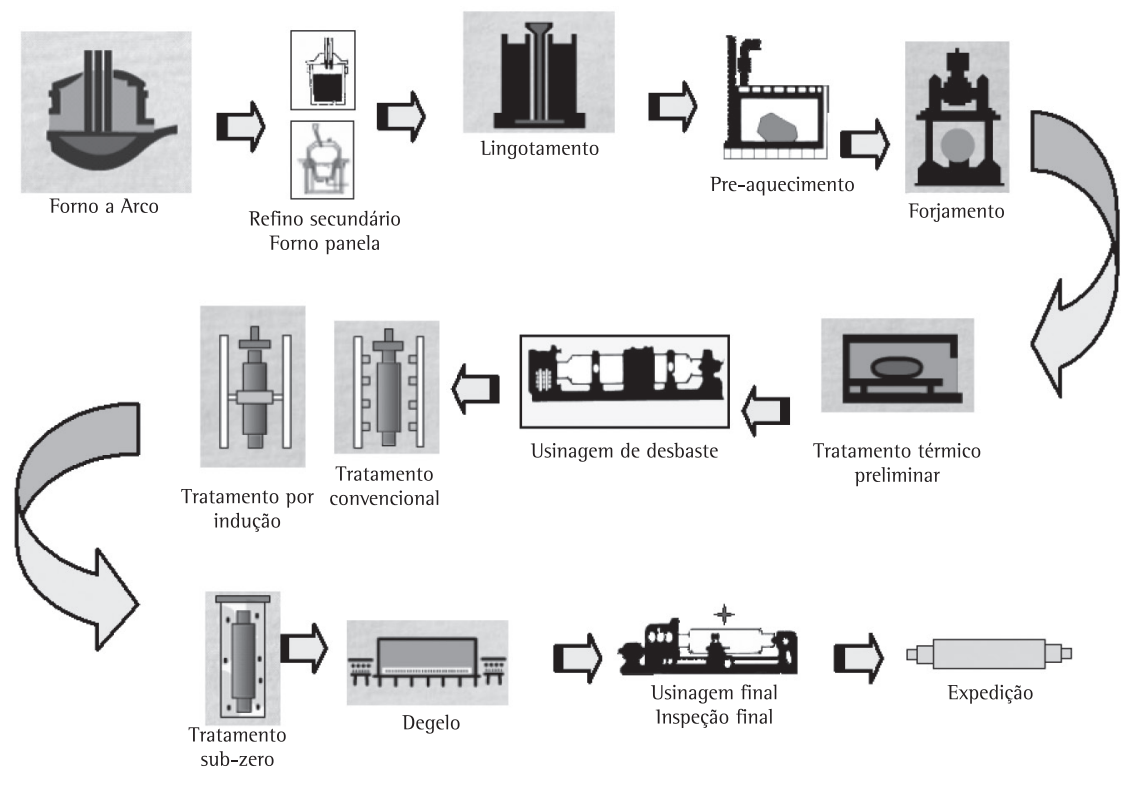

Figura 5. Sequência da produção de cilindros forjados.

térmico. A Figura 6 apresenta esquema com a sequência do fluxo de operações ao longo da UTT.

Os cilindros, ao entrarem na UTT, são armazenados no estoque de entrada. A partir daí, o processo pode ser dividido em três partes: a preparação para o tratamento térmico, o tratamento térmico e a usinagem final.

Durante a fase de preparação para o tratamento térmico, os cilindros passam por uma mandriladora para receber os furos de centro. A seguir, eles são encaminhados para os tornos de desbaste (gargalo do sistema) e de acabamento. Depois da passagem pelo torno de acabamento, o cilindro ainda passa por um outro torno que realiza as operações de faceamento e de furação dos centros. Finalmente, após a realização de todas essas etapas, o cilindro está pronto para ser tratado termicamente.

A fase de tratamento térmico tem início com a realização de um pré-aquecimento, o qual é seguido, na maioria dos casos, pelos processos de têmpera por indução (TPI), subzero e degelo. Após o degelo, eles são encaminhados para os fornos de revenimento. $\mathrm{Na}$ fase de usinagem final, os cilindros passam novamente pelo torno de face/centro, sendo, a seguir, encaminhados para o torno de acabamento. Depois do torno de acabamento, eles devem ser retificados e fresados, não importando qual dos dois processos será realizado primeiro. Após a passagem pelos processos de retificação e fresamento, os cilindros estão prontos para serem embalados e transportados para seu comprador.

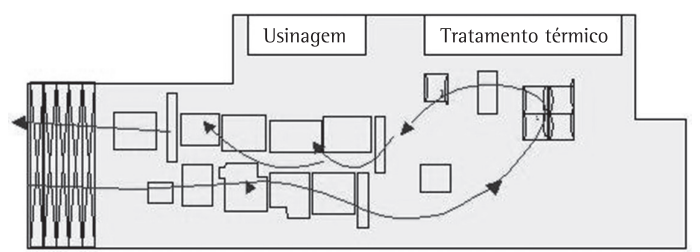

Figura 6. Sequência do fluxo de operação.

\subsection{Modelo de planejamento/gestão da produção}

\subsubsection{Descrição do sistema real e elaboração do modelo de PLI}

Como a Forjaria tem uma capacidade de produção muito maior do que a da UTT (essa capacidade não será revelada por confidencialidade) e como ela é capaz de manter o setor de usinagem e tratamento térmico abastecido ininterruptamente, ela não foi considerada uma restrição.

0 modelo de PLl foi elaborado com base na capacidade do equipamento gargalo: cada torno de desbaste opera efetivamente 18 horas por dia. Como há dois tornos de desbaste, pode-se definir mais uma restrição do sistema: a soma dos tempos de desbaste dos cilindros que serão usinados num mesmo dia não deve exceder 36 horas. Esta simplificação pode ser adotada, pois este é um processo contínuo, que possui um tempo máximo de operação de 9 horas. 
Embora esta formulação não garanta dois sublotes de 18 horas, na prática essa simplificação é possível, uma vez que se pode antecipar o início da produção de um lote seguinte no torno que ficou "ocioso". Não é necessário esperar a conclusão de um lote nos dois tornos para dar início à produção do lote seguinte.

Analisando o setor de tratamento térmico foi possivel encontrar outra restrição: os fornos de pré-aquecimento e de revenimento têm capacidade para cinco cilindros.

Assim, foram escolhidas como as variáveis de decisão as variáveis binárias $C_{i, j}$ em que $i$ se refere ao número do cilindro a ser agrupado e $j$ ao número do lote de usinagem a que pertence esse cilindro. A Função Objetivo foi maximizar o tempo de utilização dos tornos:

$\operatorname{Max} T=\sum_{i=1}^{m} \sum_{j=1}^{n} T_{i} \cdot C_{i, j}$, onde $T i$ é o tempo de usinagem do cilindro $i$

As restrições foram:

Cada cilindro pode pertencer a um único lote:

$\sum_{j=1}^{n} C_{i, j} \leq 1(i=1,2, \ldots, m) m$ : número total de cilindros;

${ }_{j=1}$ A soma dos tempos de usinagem num mesmo lote não deve exceder 36 horas:

$$
\sum_{\substack{i=1 \\ \text { lotes; }}}^{m} T_{i} \cdot C_{i, j} \leq 36(j=1,2, \ldots, n) n \text { : número total de }
$$
lotes;

A soma dos pesos dos lingotes de uma corrida (descontadas as perdas do processo) não deve exceder $86 \mathrm{t}$ :

$$
\sum_{i=1}^{m} P_{i} \cdot C_{i, j} \leq 86000(j=1,2, \ldots, n) ; \mathrm{e}
$$

Cada lote deve ter, no máximo, 5 cilindros:

$$
\sum_{i=1}^{m} C_{i, j} \leq 5(j=1,2, \ldots, n) \text {. }
$$

Uma vez elaborado, o modelo de PLl foi implantado no Excel, utilizando a ferramenta Solver ${ }^{\circledR}$. Como resultado, foi gerada uma solicitação de lingotes (Figura 7) que foi utilizada posteriormente para alimentar o modelo de simulação.

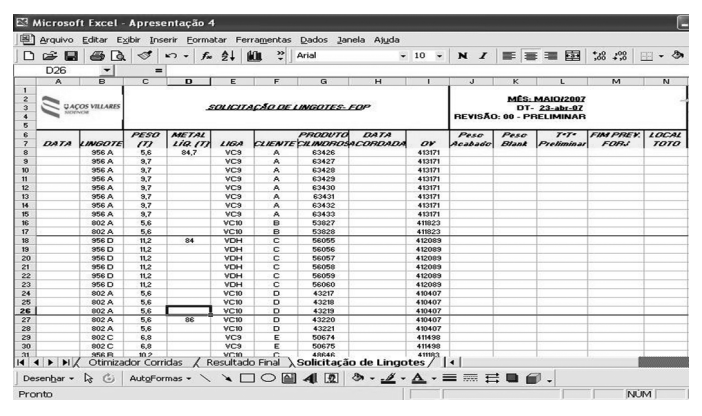

Figura 7. Solicitação de lingotes final.

\subsection{Modelo de simulação no software Arena ${ }^{\circledR}$}

Após a elaboração do modelo de PLl e de sua implantação no Solver ${ }^{\circledR}$, foram obtidos lotes de usinagem que maximizavam a ocupação dos tornos sem criar filas excessivas ou desabastecimento no equipamento gargalo.

Entretanto, o modelo de PLl desenvolvido neste trabalho não permite, por si só, observar se haverá alguma interferência durante o processo de fabricação. Da mesma forma, ele não é capaz de prever, com precisão, a data em que os cilindros ficarão prontos.

Embora, em teoria, fosse possivel criar um modelo de PLl que abrangesse toda a linha de produção, a dimensão e a complexidade do sistema analisado inviabilizariam seu uso no dia a dia da empresa estudada, uma vez que não haveria tempo de resposta suficiente diante das necessidades do departamento de Planejamento.

Dessa forma, decidiu-se construir um modelo mais simples de PLI, focado no ponto crítico do sistema, em conjunto com um modelo de simulação no software Arena ${ }^{\circledR}$, que tem como objetivo abordar o dinamismo e os detalhes do sistema. Essa solução proposta permite reduzir o tempo de análise e de resposta aos problemas.

Para isso, foram elaborados o modelo formal do sistema e, a seguir, o modelo computacional.

\subsubsection{Definição do modelo formal}

Os componentes do modelo descritos anteriormente são as máquinas-ferramenta, os fornos e os cilindros. Serão considerados somente os setores de usinagem e tratamento térmico, assumindo que os setores de lingotamento e de forjamento garantem o abastecimento da linha.

0 modelo formal é apresentado inicialmente sem muitos detalhes, sendo mostrados apenas os submodelos que o compõem (Figura 8); a título de exemplo, também é apresentado o submodelo preparação para tratamento térmico (Figura 9).

\subsubsection{Modelagem do cenário usando ARENA ${ }^{\circledR}$}

A modelagem do cenário utilizou a configuração de blocos ou módulos do software Arena ${ }^{\circledR}$ versão 10. 0 setor da usinagem foi modelado utilizando os recursos de programação do software Arena ${ }^{\circledR}$ (Figura 10), tendo como base o método proposto na seção 3, o modelo de PLl, o modelo formal e o conceito de equipamento gargalo (BLACKSTONE, 2001). 


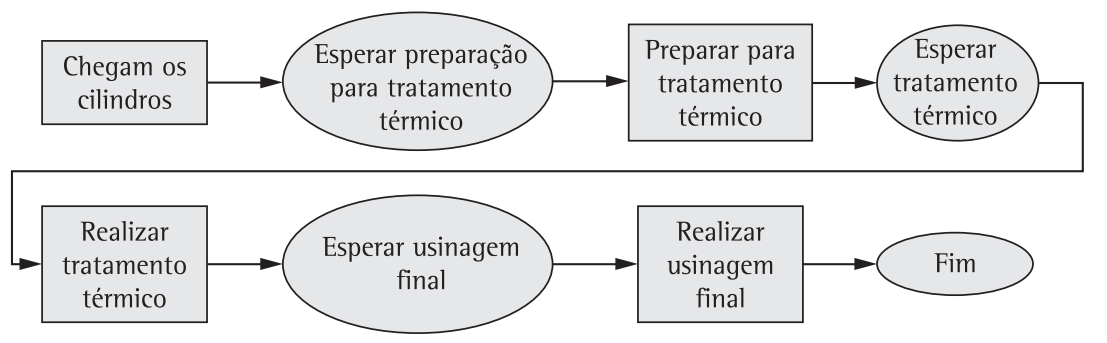

Figura 8. Modelo formal das fases fundamentais do processo.

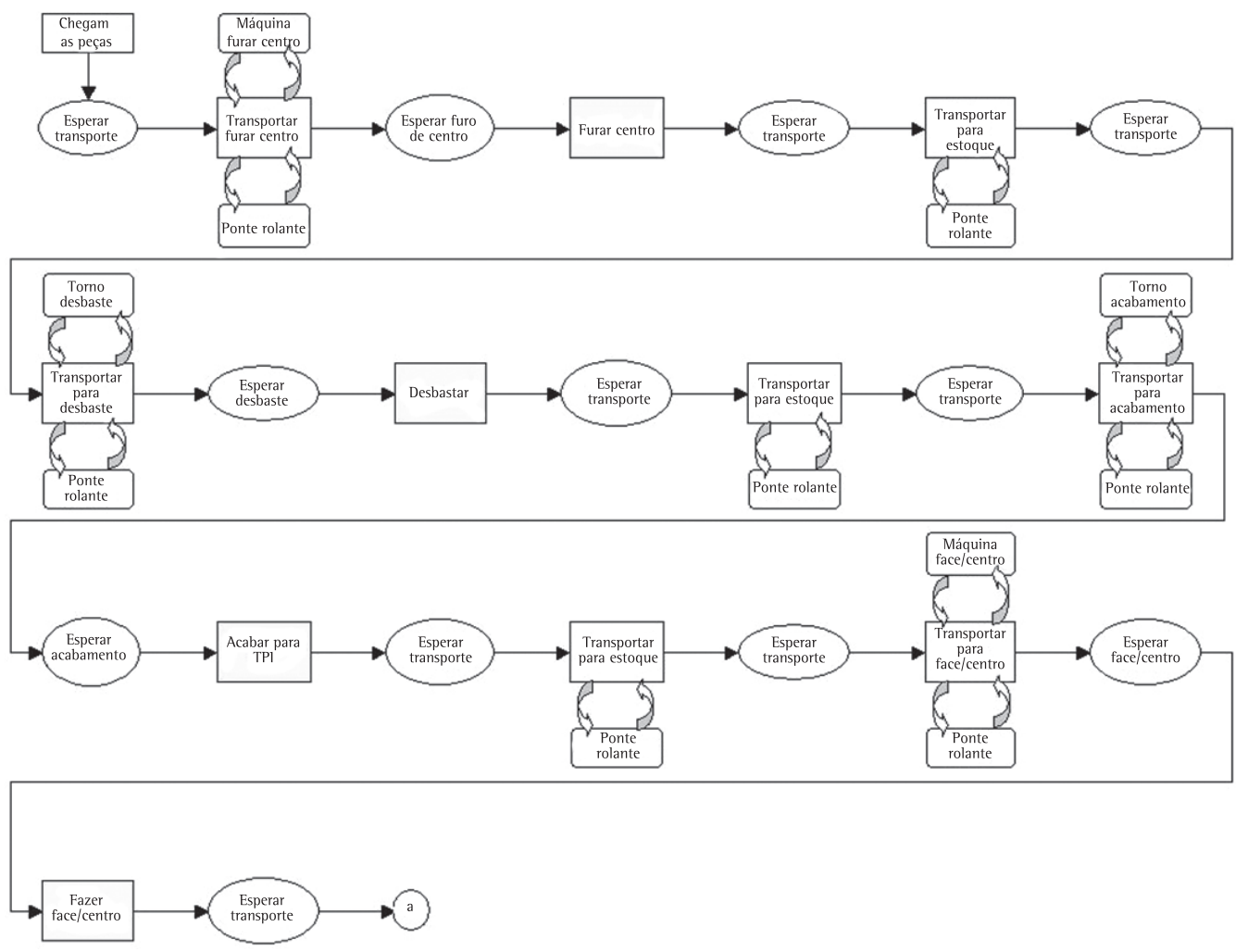

Figura 9. Modelo formal para a fase de preparação para tratamento térmico.

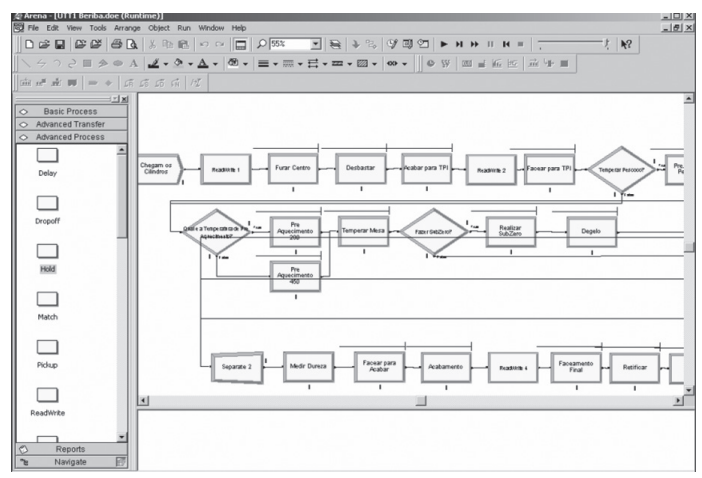

Figura 10. Modelagem através do Arena ${ }^{\circledR}$.

Os dados de entrada para o modelo de simulação foram os resultados do modelo de PLl e as informações contidas no sistema SAP da empresa, conforme
Tabela 2 (dados representados por letras não são apresentados por confidencialidade). Tais informações contemplam os tempos de processo de usinagem, as temperaturas e tempos de tratamento térmico.

\subsubsection{Validação do modelo}

Primeiramente, foi determinado o período de aquecimento (warm-up) do modelo computacional $=10$ dias. Na sequência, determinou-se o número de replicações a ser utilizado em cada simulação, utilizando-se a Equação 2. Para isso, foi analisado o histórico do sistema real para estimar a média e o desvio padrão do número de cilindros produzidos no período de um mês (os dados utilizados foram de 14 meses). Os dados e resultados estão apresentados na Tabela 3. 
Tabela 2. Dados de entrada Tabela 1 do Arena ${ }^{\circledR}$.

\begin{tabular}{|c|c|c|c|c|c|c|c|c|c|}
\hline Cilindro & OV & $\begin{array}{l}\text { Temperatura } \\
\text { aquecimento } \\
\left({ }^{\circ} \mathrm{C}\right)\end{array}$ & $\begin{array}{l}\text { Temperatura } \\
\text { revenimento } \\
\left({ }^{\circ} \mathrm{C}\right)\end{array}$ & $\begin{array}{c}\text { Têmpera } \\
\text { pescoço }\left({ }^{\circ} \mathrm{C}\right)\end{array}$ & $\begin{array}{c}\text { Subzero } \\
\left({ }^{\circ} \mathrm{C}\right)\end{array}$ & Furar & $\begin{array}{l}\text { Desbastar } \\
\text { (h) }\end{array}$ & $\begin{array}{c}\text { Acabar } \\
\text { para TPI } \\
\text { (h) }\end{array}$ & $\begin{array}{l}\text { Face } \\
\text { centro } \\
\text { (h) }\end{array}$ \\
\hline 48213 & 411127 & A & $x$ & 0 & 0 & 1,5 & 6 & 3 & 1 \\
\hline 59218 & 412503 & A & $Y$ & 0 & - & 1,5 & 7 & 4 & 1 \\
\hline 59219 & 412503 & B & $\mathrm{Z}$ & 0 & - & 1,5 & 7 & 4 & 1 \\
\hline 63227 & 413129 & A & $X$ & Y & - & 1,5 & 5 & 3 & 1 \\
\hline 59220 & 412503 & B & $\mathrm{Z}$ & 0 & - & 1,5 & 7 & 4 & 1 \\
\hline 59221 & 412503 & B & $\mathrm{Z}$ & 0 & - & 1,5 & 4,5 & 4 & 1 \\
\hline Cilindro & OV & Temperar mesa & Degelo & Revenir & Face centro & $\begin{array}{c}\text { Acabamento } \\
\text { (h) }\end{array}$ & Face centro & Retifica (h) & Fresar \\
\hline 48213 & 411127 & 2,5 & 0 & C & 2 & 8 & 4 & 8 & 6 \\
\hline 59218 & 412503 & 2,5 & $\mathrm{D}$ & C & 2 & 8 & 5 & 10 & 9 \\
\hline 59219 & 412503 & 2,5 & $\mathrm{D}$ & $\mathrm{C}$ & 2 & 8 & 5 & 20 & 9 \\
\hline 63227 & 413129 & 2,5 & $\mathrm{D}$ & $\mathrm{D}$ & 2 & 10 & 3 & 8 & 8 \\
\hline 59220 & 412503 & 2,5 & $\mathrm{D}$ & $\mathrm{D}$ & 2 & 7 & 5 & 9 & 9 \\
\hline 59221 & 412503 & 2,5 & $\mathrm{D}$ & $\mathrm{D}$ & 2 & 7 & 5 & 9 & 9 \\
\hline
\end{tabular}

Executando-se o modelo computacional e realizando-se as 7 replicações, encontrou-se uma média de 128 cilindros/mês. Como $128<130$, foi necessário repetir o procedimento anterior. 0 número de replicações novamente encontrado foi 7. Realizando-se a nova simulação, encontrou-se uma média de 128 cilindros/mês. Assim, o número de replicações a ser realizado em cada simulação do modelo computacional foi de 7 replicações.

Definido o número de replicações, o passo seguinte foi validar o modelo computacional. Para essa validação foram considerados apenas os meses isentos de causas especiais (paradas para manutenção, por exemplo). A Tabela 4 apresenta a produção nos meses isentos de causas especiais.

Para validar o modelo computacional, foram realizadas simulações com os dados históricos da empresa. A seguir, os resultados das simulações foram comparados com os valores da produção real, mês a mês. A Tabela 5 mostra os resultados das 7 replicações realizadas no mês $A$.

Utilizou-se o teste de hipóteses de uma média com o desvio padrão desconhecido, conforme a Equação 1:

Para um risco $\alpha=5 \%$ :

$$
\begin{aligned}
& \left\{\begin{array}{l}
H_{0}: \mu_{\text {modelo }}=130 \\
H_{1}: \mu_{\text {modelo }} \neq 130
\end{array}\right. \\
& t_{\text {calculado }}=\frac{\bar{x}-\mu}{s / \sqrt{n}}=\frac{128-130}{3,185 / \sqrt{7}} \Rightarrow t_{\text {calculado }}=1,66 \\
& t_{\text {critico }}=t_{6 ; 2,5 \%}=2,447
\end{aligned}
$$

Como $t_{\text {calculado }}<t_{\text {crítico }}, \mathrm{H}_{0}$ não foi rejeitada. Portanto, a média do número de cilindros produzidos no mês A, obtida através do modelo computacional, pode ser considerada igual à quantidade produzida pelo
Tabela 3. Resultado para determinar o número de replicações.

$\begin{array}{cc}\text { Média (14 meses) } & 130 \\ \text { Desvio padrão (14 meses) } & 4,81 \\ r \text { (Precisão desejada) } & 3 \% \\ 1-\alpha \text { (Nível de confiança) } & 5 \% \\ n \text { (Número de replicações) } & 7\end{array}$

Tabela 4. Histórico da quantidade de cilindros produzidos nos meses isentos de causas especiais.

\begin{tabular}{ccccccccc}
\hline Mês & A & B & C & D & E & F & G & H \\
\hline Produção & 130 & 129 & 130 & 131 & 130 & 129 & 131 & 130 \\
\hline
\end{tabular}

Tabela 5. Resultados da simulação para o mês após 7 replicações.

\begin{tabular}{cccccccc}
\hline Replicação & $\mathbf{1}$ & $\mathbf{2}$ & $\mathbf{3}$ & $\mathbf{4}$ & $\mathbf{5}$ & $\mathbf{6}$ & $\mathbf{7}$ \\
\hline Produção & 123 & 129 & 128 & 132 & 131 & 129 & 125 \\
Média $=$ & 128 & \multicolumn{5}{c}{ Desvio padrão $=3,185$} \\
\hline
\end{tabular}

Tabela 6. Validação do modelo computacional.

\begin{tabular}{ccccc}
\hline Mês & $\begin{array}{c}\text { Produção } \\
\text { real }\end{array}$ & $\begin{array}{c}\text { Produção } \\
\text { simulada }\end{array}$ & $\begin{array}{c}\text { Desvio } \\
\text { padrão }\end{array}$ & $t_{\text {calculado }}$ \\
\hline A & 130 & 128 & 3,185 & 1,66 \\
B & 129 & 128 & 3,393 & 0,78 \\
C & 130 & 131 & 2,436 & 1,09 \\
D & 131 & 130 & 3,486 & 0,76 \\
E & 130 & 128 & 3,053 & 1,73 \\
F & 129 & 131 & 2,597 & 2,04 \\
G & 131 & 132 & 3,718 & 0,71 \\
H & 130 & 130 & 2,934 & 0 \\
\hline
\end{tabular}

sistema real. Repetindo-se o procedimento para os demais meses, obtém-se a Tabela 6 .

Todos os valores de $t_{\text {calculado }}$ foram menores que 0 valor de $t_{\text {critico }}$. Assim, para um risco $\alpha$ de $5 \%$, pôde-se dizer que o modelo criado reproduziu de maneira 
satisfatória o comportamento do sistema real e o modelo foi, portanto, validado.

Esse modelo foi utilizado para determinar a sequência de usinagem do equipamento gargalo (no caso, o torno de acabamento), definindo o momento de entrada dos cilindros para o tratamento térmico e para a usinagem final.

Além disso, o modelo foi utilizado para prever a data de saída dos cilindros e para analisar o comportamento do sistema quando novos recursos forem adicionados à linha de produção.

\subsection{Apresentação e discussão dos resultados}

Os resultados deste trabalho podem ser divididos basicamente em duas partes. A primeira parte refere-se aos resultados obtidos com o modelo de planejamento/gestão da produção; a segunda, aos resultados obtidos com o modelo de simulação.

\subsubsection{Resultados obtidos a partir do modelo de planejamento/gestão da produção}

A aplicação do modelo de planejamento/gestão da produção trouxe os seguintes resultados:

- Melhor agrupamento entre os cilindros com características semelhantes - lsso melhorou a ocupação dos fornos de tratamento térmico, reduziu o número de set-ups e homogeneizou o número de horas dos lotes de usinagem das corridas. A Figura 11 mostra os tempos de desbaste por lote, obtidos pela aplicação do Solver ${ }^{\circledR}$ e aqueles obtidos manualmente para um determinado mês; e

- Melhoria na data de acerto dos cilindros - Foi realizada uma comparação entre as médias de acerto antes e após a implantação do modelo de planejamento/gestão, utilizando o método de Aspin-Welch. 0 resultado encontra-se na Tabela 7.

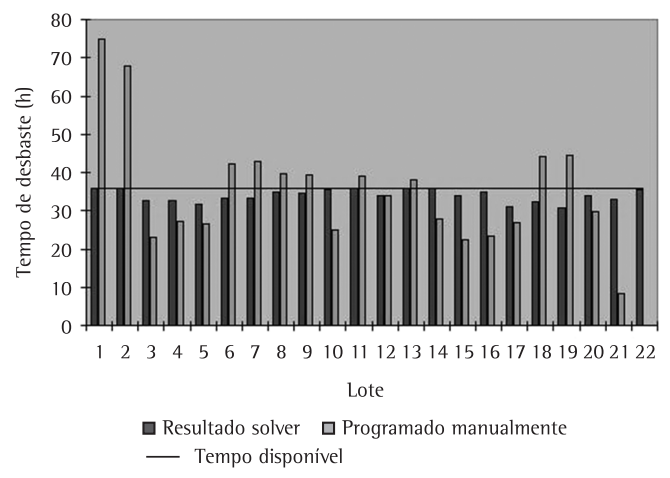

Figura 11. Tempos de desbaste por lote, obtidos pelo Solver ${ }^{\circledR}$ e obtidos manualmente.
Como $t_{\text {calculado }}>t_{\text {critico }}, \mathrm{H}_{0}$ pode ser rejeitada. Portanto, pode-se afirmar, com $\alpha=5 \%$, que houve uma melhoria no acerto da data de remessa após a implantação do modelo de planejamento/gestão da produção. A taxa de acertos aumentou de 66\% para 71\% (em média).

- Definição da sequência de nascimento dos cilindros (solicitação de lingotes) - Oque viabiliza e facilita o emprego do modelo de simulação.

\subsubsection{Resultados obtidos a partir do modelo de simulação}

0 software Arena ${ }^{\circledR}$ gera um relatório de resultados para todas as simulações realizadas. Esse relatório exibe informações como o número de cilindros produzidos, a ocupação média dos equipamentos e o tempo e tamanho médio das filas.

Além dos resultados obtidos nesse relatório, os seguintes resultados adicionais foram alcançados:

- Com a utilização dessa solução (simulação-otimização), foi possível fazer a gestão de um equipamento que não era gargalo do sistema (torno de acabamento), mas que tinha potencial de provocar interferências em todo o sistema se fosse mal administrado. Conforme explicado no item 4.1, esse equipamento participa do processo em dois momentos distintos (preparação para tratamento térmico e acabamento para retíficas). Se não houver um bom sincronismo entre as duas etapas, poderá ocorrer um desabastecimento de parte da linha de produção.

A Tabela 8 exibe a sequência em que os cilindros devem ser processados nos tornos de acabamento de forma a diminuir a probabilidade de ocorrer

Tabela 7. Resultado do método Aspin-Welch.

\begin{tabular}{cccccccccc}
\hline & Média & $\begin{array}{c}\text { Desvio } \\
\text { padrão }\end{array}$ & Variância & $\mathrm{n}$ & $\mathrm{w}$ & $\mathrm{v}$ & $\boldsymbol{t}_{\text {calc }}$ & $\mathrm{t}_{10 ; 2,5 \%}$ \\
\hline $\begin{array}{c}\text { Antes da } \\
\text { implantação } \\
\begin{array}{c}\text { Após a } \\
\text { implantação }\end{array}\end{array}$ & 85,6 & 4,2 & 17,6 & 7 & 2,52 & & \\
\hline
\end{tabular}

Tabela 8. Fluxo de produção dos tornos de acabamento.

\begin{tabular}{cc}
\hline Número do cilindro & Ir para \\
\hline 50591 & Tratamento térmico \\
50931 & Tratamento térmico \\
54834 & Tratamento térmico \\
54835 & Tratamento térmico \\
63227 & Acabamento \\
59218 & Acabamento \\
59219 & Acabamento \\
54996 & Tratamento térmico \\
59220 & Tratamento térmico \\
\hline
\end{tabular}


desabastecimento dos equipamentos, garantindo uma maior continuidade do fluxo de produção.

- Previsão da data em que o cilindro ficará pronto. A Tabela 9 ilustra a saída gerada pelo software Arena ${ }^{\circledR}$;

- Melhoria no acerto da data de remessa dos cilindros. A Tabela 10 mostra a taxa de acerto antes e após a implementação do modelo no sistema e a Tabela 11 mostra a comparação entre as médias antes e após implementação do modelo computacional (método Aspin-Welch). Como $t_{\text {calculado }}>t_{\text {criticio, }}, \mathrm{H}_{0}$ pode ser rejeitado. Portanto, pode-se afirmar, com $\alpha=5 \%$, que há uma melhoria do acerto da data de remessa após a implantação do modelo de planejamento/ gestão da produção. A taxa de acerto aumentou de 93 para 118 cilindros por mês (em média) ou, em termos percentuais, de $71 \%$ para $91 \%$, reduzindo o número de reprogramações de embarque e proporcionando melhor atendimento ao cliente; e

Tabela 9. Data de remessa dos cilindros.

\begin{tabular}{cc}
\hline Cilindro & Data de remessa \\
\hline 59343 & $1 / 8 / 2007$ \\
59318 & $1 / 8 / 2007$ \\
59319 & $2 / 8 / 2007$ \\
57458 & $2 / 8 / 2007$ \\
56190 & $2 / 8 / 2007$ \\
56191 & $3 / 8 / 2007$ \\
45980 & $3 / 8 / 2007$ \\
51586 & $3 / 8 / 2007$ \\
\hline
\end{tabular}

Tabela 10. Acerto na data de remessa dos cilindros.

\begin{tabular}{cccc}
\hline & Mês & Acerto (\%) & $\begin{array}{c}\text { Acerto (quantidade } \\
\text { de cilindros) }\end{array}$ \\
\hline Antes da & $5 /$ jul. & 70 & 91 \\
implantação & $6 /$ jul. & 73 & 95 \\
& $7 /$ jul. & 71 & 92 \\
Após a & $8 /$ jul. & 89 & 116 \\
implantação & $9 /$ jul. & 92 & 120 \\
\hline
\end{tabular}

Tabela 11. Resultado do método Aspin-Welch.

\begin{tabular}{cccccccccc}
\hline & Média & $\begin{array}{c}\text { Desvio } \\
\text { padrão }\end{array}$ & Variância & $\mathrm{nN}$ & $\mathbf{w}$ & $\mathrm{v}$ & $\boldsymbol{t}_{\text {calc }}$ & $\mathbf{t}_{3 ; 2,5 \%}$ \\
\hline $\begin{array}{c}\text { Antes da } \\
\text { implantação } \\
\begin{array}{c}\text { Após a } \\
\text { implantação }\end{array}\end{array}$ & 92,7 & 2,08 & 4,33 & 3 & 3 & & & \\
\hline
\end{tabular}

Tabela 12. Resultados da simulação para o novo cenário.

\begin{tabular}{|c|c|c|c|c|c|c|c|}
\hline Replicação & 1 & 2 & 3 & 4 & 5 & 6 & 7 \\
\hline Produção & 138 & 141 & 139 & 141 & 146 & 143 & 146 \\
\hline \multicolumn{4}{|c|}{ Média $=142$} & \multicolumn{4}{|c|}{ Desvio padrão = 3,162 } \\
\hline
\end{tabular}

- Previsão da nova capacidade da UTT após aquisição de novo torno de acabamento: realizando nova simulação com um torno de acabamento a mais, foram obtidos os resultados (quantidade de cilindros produzida em cada uma das 7 replicações) da Tabela 12.

0 intervalo de confiança foi obtido pela Equação 3, substituindo-se $\sigma$ por $s$ e a distribuição normal pela distribuição t-Student:

$$
\begin{aligned}
& t_{6 ; 2,5 \%} \frac{s}{\sqrt{n}}=2,447 \cdot \frac{3,162}{\sqrt{7}}=2,92 \\
& P(142-2,92 \leq \mu \leq 142+2,92)=1-0,05 \\
& P(139,08 \leq \mu \leq 144,92)=95 \%
\end{aligned}
$$

Portanto, após 7 replicações, o modelo indica, com 95\% de confiança, que o novo sistema terá uma capacidade de 139 a 145 cilindros por mês.

\section{Conclusão}

Este trabalho visou a redução dos tempos mortos com aumento da produtividade da área analisada. A aplicação e a implantação do método aqui descrito, na empresa siderúrgica que foi objeto do estudo, geraram resultados satisfatórios, pois o melhor gerenciamento do gargalo possibilitou prever, com maior exatidão, o fluxo da produção, garantindo um fluxo contínuo e melhor previsibilidade do acerto do prazo de entrega ao cliente. Os resultados gerados pela simulação alimentam um quadro de gestão à vista, para que os operadores do equipamento gargalo possam seguir o fluxo proposto.

A melhoria no acerto da data final do produto (de $70 \%$ para 90\%) facilitou o fluxo logístico de entrega ao cliente final. Uma vez que $80 \%$ da produção destinam-se ao mercado externo, o aumento na taxa de acerto permite realizar a reserva dos navios (95\% da produção utiliza a modalidade marítima para a exportação) com maior antecedência do que anteriormente.

Além dos ganhos acima citados, a aplicação da simulação ajudou a planejar a gestão da produção antes da execução, trazendo novos insights, que contribuirão para o melhor entendimento dos problemas que podem comprometer o desempenho dos recursos gargalos.

Finalmente, vale ressaltar que o papel da manufatura pode ser visto como uma arma de competitividade das empresas. A utilização correta da PLl e da simulação, como apresentado neste trabalho, é uma forma eficaz de melhorar o planejamento da produção, com melhor previsibilidade dos prazos de entrega e, consequentemente, melhor atendimento do cliente. 


\section{Referências}

ARENALES, M. et al. Pesquisa Operacional - Modelagem e Algoritmos. Rio de Janeiro: Elsevier, 2007.

AZADIVAR, F. Simulation optimization methodologies. In: WINTER SIMULATION CONFERENCE, 31., 1999, Phoenix. Proceedings... Phoenix, 1999. v. 1, p. 93-100.

$\mathrm{BALCl}, \quad 0$. Verification, validation and accreditation of simulation models. In: WINTER SIMULATION CONFERENCE, 1997, Atlanta. Proceedings... Atlanta, 1997.

BATEMAN, R. E.; BOWDEN, R. 0. Simulação Otimizando os Sistemas. 2. ed. São Paulo: Imam, 2002.

BLACKSTONE, J. H. Theory of Constraints - a status report.International Journal of Production Research, v. 39, n. 6, p. 1053-1080, 2001. http://dx.doi. org/10.1080/00207540010028119

BUSH, A.; BILES, W. E.; DEPUY, G. W. Iterative optimization and simulation of barge traffic on an inland waterway. In: WINTER SIMULATION CONFERENCE, 2003, New Orleans. Proceedings... New Orleans, 2003. p. 1751-1756.

CARDOSO, D. F.; VINHOZA, T. T. V.; SAMPAIO NETO, R. A simulação como ferramenta de auxílio na avaliação de um sistema de comunicação CDMA com multiplas portadoras. In: SIMPÓSIO DE PESQUISA OPERACIONAL E LOGÍSTICA DA MARINHA, 10., 2007, Rio de Janeiro. Anais... SPOLM, 2007.

CEClliano, W. R. A. Aplicação de um método de simulação-otimização na cadeia produtiva de minérios de ferro. 2007. 209 f. Dissertação (Mestrado em Engenharia de Sistemas Logísticos)-Escola Politécnica da Universidade de São Paulo, São Paulo, 2007.

CHWIF, L; MEDINA, A. C. Modelagem e simulação de eventos discretos: teoria e aplicações. São Paulo: Bravarte, 2006.

COSTA NETO, P. L. 0. Estatística. 2. ed. São Paulo: Edgard Blucher, 2002. 266 p.

FERNANDES, L. J. Aplicação dos conceitos da teoria das restrições, programação linear inteira (PLI) e simulação em uma indústria siderúrgica. 2008. 149 f. Dissertação (Mestrado em Ciências)-Instituto Tecnológico de Aeronáutica, São José dos Campos, 2008.

FU, M. C. Optimization for Simulation: Theory vs. Practice. Journalon Computing, v. 14, n. 3, 2002.

GAVIRA, M. O. Simulação computacional como uma ferramenta de aquisição de conhecimento. 2003. 150 f. Dissertação (Mestrado em Engenharia de Produção)-Universidade de São Paulo, São Paulo, 2003.

GRANGER, J.; KRISHNAMURTHY, A.; ROBINSON, S. M. Approximation and optimization for stochastic networks.
Berlim: Dynamic Stochastic Optimization, 2002. p. 67-79.

HILlIER, F. S.; LIEBERMAN, G. J. Introdução à Pesquisa Operacional. 8. ed. São Paulo: McGraw-Hill, 2006. 828 p.

KÖCHEL, P.; KUNZE, S.; NIELÄNDER, U. Optimal control of a distributed service system with moving resources: application to the fleet sizing and allocation problem. International Journal Production Economics, v. 81-82 p. 443-459, 2003. http://dx.doi.org/10.1016/S09255273(02)00287-6

LACHTERMACHER, G. Pesquisa Operacional na Tomada de Decisões. Rio de Janeiro: Campus, 2004.

MONTEVECHI, J. A. B. et al. Análise comparativa entre regras heurísticas de sequenciamento da produção aplicada em job shop. Produto \& Produção, v. 6, n. 2, p. 12-18, 2002.

MORITO, S. et al. Simulation based constraint generation with applications to optimization of logistic system design. In: WINTER SIMULATION CONFERENCE, 31., 1999, Phoenix. Proceedings... Phoenix, 1999. v. 1, p 531-536.

OLIVEIRA, F. A.; DUARTE, R. N.; MONTEVECHI, J. A. B. 0 reflexo da mudança organizacional sobre o desempenho de uma empresa de autopeças: estudo de caso. In: ENCONTRO NACIONAL DE ENGENHARIA DE PRODUÇÃO, 22., 2002, Curitiba. Anais... Curitiba: PUC-PR, 2002.

PAIVA, A. F. 0. Geração automática de modelos de simulação de uma linha de produção na indústria têxtil. 2005. 225 f. Dissertação (Mestrado em Engenharia Industrial)-Universidade do Minho, Guimarães, 2005.

PAPADOPOULOS, H. T.; HEAVEY, C.; BROWNE, J. Queueing Theory in Manufacturing Systems Analysis and Design. London: Chapman \& Hall, 1993.

PEIXOTO, E. C. Planejamento de pedidos de compra e estoque de insumos a partir de previsão agregada de vendas e histórico de demanda utilizando simulação. 2006. 70 f. Dissertação (Mestrado em Engenharia de Produção)-Universidade Federal de Minas Gerais, Belo Horizonte, 2006.

PINHO, A. F. Metodologia para utilização de algoritmos genéticos em modelos de simulação computacional em ambientes de manufatura. 2008. 189 f. Tese (Doutorado em Engenharia Mecânica)-Universidade Estadual Paulista, Guaratinguetá, 2008.

PINTO JUNIOR, O. P. F. Simulação e otimização: desenvolvimento de uma ferramenta de análise de decisão para suprimento de refinarias de petróleo através de uma rede de oleodutos. 2001. 131 f. Dissertação (Mestrado em Engenharia de Produção)-Universidade Federal de Santa Catarina, Florianópolis, 2001.

\title{
Production management of rolling mill rolls: a quantitative study case
}

\begin{abstract}
This article presents a simulation-optimization model application for a real case study in the rolling mill roll sector of a steel plant. The purpose of this study was to get a better area/equipment bottleneck management in the production line. The simulation was used together with an ILP (Integer linear Programming) optimization model, in order to improve customer service in a made-to-order production. As a result of this ILP and Simulation combined approach, the productive process was optimized and both queues and lead-time were reduced, improving customer service.
\end{abstract}

Keywords

Integer linear programming (ilp). Simulation-optimization method. Rolling mill rolls. Made-to-order production. 


\section{Errata}

Errata do artigo "Planejamento e controle da produção de cilindros para laminação: um estudo de caso quantitativo" (http://dx.doi.org/10.1590/S0103-65132012005000061) publicado em ahead of print em 04 de setembro de 2012.

A referência apresentada no artigo esta incorreta:

BATEMAN, R. E.; BOWDEN, ROYCE 0. Simulação Otimizando os Sistemas. 2. ed. São Paulo: Imam, 2002.

Correção da referência:

BATEMAN, R. E.; BOWDEN, R. 0. Simulação Otimizando os Sistemas. 2. ed. São Paulo: Imam, 2002.

As citações presentes no artigo estão incorretas:

(BATEMAN; BOWDEN; ROYCE, 2002)

Correção da citação:

(BATEMAN; BOWDEN, 2002).

A referência apresentada no artigo esta incorreta:

PAPADOPOULOS, H. T.; HEVEY, C.; BROWNE, J. Queueing Theory in Manufacturing Systems Analysis and Design. London: Chapman \& Hall, 1993.

Correção da referência:

PAPADOPOULOS, H. T.; HEAVEY, C.; BROWNE, J. Queueing Theory in Manufacturing Systems Analysis and Design. London: Chapman \& Hall, 1993.

A citação apresentada no artigo esta incorreta:

(GRANGER; KRISHNAMURTH; ROBINSON, 2002)

Correção da citação:

(GRANGER; KRISHNAMURTHY; ROBINSON, 2002) 